\title{
Rapid glucocorticoid-induced activation ofTRP and CB1 receptors causes biphasic modulation of glutamate release in gastric-related hypothalamic preautonomic neurons
}

\author{
Carie R. Boychuk ${ }^{1 \dagger}$, Andrea Zsombok ${ }^{1 \dagger}$, Jeffrey G. Tasker ${ }^{2}$ and Bret N. Smith ${ }^{1 *}$ \\ ${ }^{1}$ Department of Physiology, University of Kentucky College of Medicine, Lexington, KY, USA \\ ${ }^{2}$ Department of Cell and Molecular Biology and Neuroscience Program, Tulane University, New Orleans, LA, USA
}

\section{Edited by:}

Kevin W. Williams, The University of Texas Southwestern Medical Center, USA

\section{Reviewed by:}

James A. Carr, Texas Tech University, USA

Gábor B. Makara, Hungarian Academy of Sciences, Hungary

R. Alberto Travagli, Penn State College of Medicine, USA

\section{${ }^{*}$ Correspondence:}

Bret N. Smith, Department of Physiology, University of Kentucky College of Medicine, MS508

Chandler Medical Center, 800 Rose Street, Lexington, KY 40536, USA. e-mail: bret.smith@uky.edu

${ }^{+}$Carie R. Boychuk and Andrea Zsombok have contributed equally to this work.
Glucocorticoids rapidly regulate synaptic input to neuroendocrine cells in the hypothalamic paraventricular nucleus (PVN) by inducing the retrograde release of endogenous messengers. Here we investigated the rapid effects of dexamethasone (DEX) on excitatory synaptic input to feeding-related, preautonomic PVN neurons using whole-cell patch-clamp recordings. In $\sim 50 \%$ of identified gastric-related preautonomic PVN neurons, DEX elicited a biphasic synaptic response characterized by an initial rapid and transient increase in the frequency of miniature excitatory postsynaptic currents (mEPSCs), followed by a decrease in mEPSC frequency within 9 min; remaining cells displayed only a decrease in mEPSC frequency. The late-phase decrease in mEPSC frequency was mimicked by the cannabinoid receptor agonists anandamide (AEA) and WIN 55,212-2, and it was blocked by the CB1 receptor antagonist AM251. The biphasic DEX effect was mimicked by AEA. The early increase in mEPSCs was mimicked by activation of transient receptor potential vanilloid type 1 (TRPV1) receptors with capsaicin and by activation of TRPV4 receptors with 4- $\alpha$-PDD. The increase was reduced, but not blocked, by selective TRPV1 antagonists and in TRPV1 knockout mice; it was blocked completely by the broad-spectrum TRPV antagonist ruthenium red and by combined application of selective TRPV1 andTRPV4 antagonists. The DEX effects were prevented entirely by intracellular infusion of the G-protein inhibitor, GDPBS. Thus, DEX biphasically modulates synaptic glutamate onto a subset of gastric-related PVN neurons, which is likely mediated by induction of a retrograde messenger. The effect includes a TRPV1/4 receptor-mediated transient increase and subsequent CB1 receptormediated suppression of glutamate release. Multiphasic modulation of glutamate input to PVN neurons represents a previously unappreciated complexity of control of autonomic output by glucocorticoids and endogenous cannabinoids.

Keywords: cannabinoid, vanilloid, paraventricular nucleus

\section{INTRODUCTION}

The paraventricular nucleus (PVN) of the hypothalamus plays a critical role in integrating neural and humoral signals leading to the coordination of neuroendocrine and autonomic motor outputs. Preautonomic PVN neurons control sympathetic and parasympathetic output via projections to the brainstem and spinal cord (Swanson and Kuypers, 1980). Anatomical and physiological evidence suggests that PVN neurons are involved in controlling energy homeostasis, including regulation of feeding behavior and digestion (Sims and Lorden, 1986). In general, inhibition of PVN neuron activity tends to induce feeding, whereas a reduction in feeding is associated with increased PVN activity (Kow and Pfaff, 1989). This is presumably mediated in large part by neural interactions with brainstem autonomic nuclei that regulate output to the stomach. Modulation of hypothalamic-brainstem circuit activity likely plays a key role in regulating feeding behavior.

Glucocorticoids can affect the hypothalamic-pituitary-adrenal (HPA) axis and also regulate feeding behavior (Tempel et al.,
1993; Dallman, 2003; Di et al., 2003). Recent findings indicate that glucocorticoids elicit a rapid inhibitory response in the PVN by inducing retrograde release of the endogenous cannabinoids (eCBs) 2-arachidonoyl glycerol (2-AG) and anandamide (AEA) from parvocellular and magnocellular neuroendocrine cells (Di et al., 2003, 2005b). These eCBs act to inhibit glutamate release, leading to a reduced excitatory synaptic drive to PVN neuroendocrine cells over the course of a few minutes (Di et al., 2005b). Cannabinoid actions in the brain are largely mediated through CB1 receptors, but AEA also activates TRPV1 in transfected cells (Zygmunt et al., 1999; Van Der Stelt and Di Marzo, 2004). Whereas $\mathrm{CB} 1$ receptors are G-protein-coupled receptors and their binding typically inhibits synaptic release, TRPV1 are ligand-coupled non-specific cation channels, whose activation at synaptic terminals typically increases transmitter release (Marinelli et al., 2003; Tominaga and Tominaga, 2005; Caterina, 2007). We recently identified dual inhibitory and excitatory effects of exogenously applied AEA on synaptic input to preautonomic neurons in the dorsal 
motor nucleus of the vagus, an effect that was mediated by binding to CB1R and TRPV1, respectively (Derbenev et al., 2004, 2006). TRPV1 receptors are expressed in the PVN (Cristino et al., 2006), and their activation appears to potentiate glutamatergic signals to PVN neurons that project to the spinal cord (Li et al., 2004). Recently, TRPV2 and TRPV4 were also identified in the hypothalamus (Guler et al., 2002; Wainwright et al., 2004; Cristino et al., 2006). Like TRPV1, TRPV4 can also be modulated by eCBs (Guler et al., 2002; Watanabe et al., 2003; Wechselberger et al., 2006). However, TRPV-mediated effects of eCBs have not previously been identified in PVN neurons.

Glucocorticoids applied in the PVN cause the release of eCB ligands from neuroendocrine PVN cells (Di et al., 2005b; Evanson et al., 2010). Since both CB1R and TRPV1 are functional in the PVN, and AEA is an agonist at both receptors and at TRPV4, we hypothesized that glucocorticoid-mediated $\mathrm{eCB}$ release activates both TRPV and CB1 receptors on presynaptic afferent terminals in PVN. Because of the known link between eCB activity and ingestive/digestive behaviors, we tested for DEX-induced modulation of miniature excitatory postsynaptic currents (mEPSCs) in gastric-related preautonomic PVN neurons identified by retrograde transsynaptic labeling from the stomach with pseudorabies virus (PRV) 152 (PRV-152), which expresses enhanced green fluorescent protein (EGFP).

\section{MATERIALS AND METHODS ANIMALS}

Male (4-8 weeks old) Sprague Dawley rats (Harlan, Indianapolis, IN, USA) and female and male B6.129 $\times 1$-Trpv1 ${ }^{\mathrm{tm} 1 \mathrm{Jul} / \mathrm{J} \text { homozy- }}$ gote mice (6-19 weeks old a gift of Dr. Y. Lee, bred from founders obtained from The Jackson Laboratory, Bar Harbor, ME, USA) were used for these experiments. Animals were housed in a vivarium under $12 \mathrm{~h}$ light, $12 \mathrm{~h}$ dark cycle with food and water available ad libitum. The University of Kentucky Animal Care and Use Committee approved all animal procedures.

\section{RETROGRADE TRANSSYNAPTIC NEURONAL TRACING}

A PRV strain isogenic with the attenuated PRV Bartha, which was constructed to report EGFP (PRV-152; a gift from L. W. Enquist, Princeton University) was used to retrogradely label neurons that were synaptically connected to the gastric musculature (Smith et al., 2000; Davis et al., 2003; Glatzer et al., 2003; Derbenev et al., 2004, 2006). Under isoflurane anesthesia, rats were inoculated with PRV-152 $\left(1 \times 10^{8} \mathrm{pfu} / \mathrm{ml}\right)$ directed tangentially into the musculature of the greater curvature of the stomach fundus $(2 \mu \mathrm{L} ; 3-4$ injections per stomach) using a Hamilton syringe fitted with a 26 -gage needle. Each injection was made over the course of $30 \mathrm{~s}$ and the needle remained in place for $1 \mathrm{~min}$ after injection. The abdominal compartment was rinsed thoroughly with sterile saline to prevent accidental labeling of other viscera (Glatzer et al., 2003; Derbenev et al., 2004, 2006). The abdominal wall was then sutured; animals recovered and were maintained in a biosafety level 2 laboratory for up to $96 \mathrm{~h}$ post-injection. The PRV-152 infects terminal fields in the stomach wall and selectively labels preautonomic central neurons retrogradely in synaptic series. Because it does not sort in axons or glial cells, the construct does not spread orthogradely or non-specifically from axons to other structures (Ch'ng et al., 2007).
Labeling sequence, timing, and other characteristics have been well-characterized for this pathway and include initial appearance of EGFP in the PVN at about $72 \mathrm{~h}$ post-inoculation, with numbers of labeled cells peaking by $96 \mathrm{~h}$ (i.e., $<24 \mathrm{~h}$ after initial neuron infection in the PVN). Central neurons infected for up to $72 \mathrm{~h}$ display no apparent adverse effects of viral infection (Smith et al., 2000; Irnaten et al., 2001; Davis et al., 2003; Glatzer et al., 2003, 2007; Derbenev et al., 2004), but this was verified in the PVN, where typical measurements of membrane potential, input resistance, action potential generation, and presence of low-threshold spikes indicative of preautonomic PVN cells were obtained (Luther and Tasker, 2000; Stern, 2001; Luther et al., 2002).

\section{PVN SLICE PREPARATION}

Acute hypothalamic slices containing the PVN were prepared from infected male Sprague Dawley rats and TRPV1 knockout mice. Animals were deeply anesthetized with halothane inhalation (Sigma, St. Louis, MO, USA) and then decapitated. The brain was removed from the cranial cavity after cutting the optic nerves and immersed in an ice-cold $\left(0-4^{\circ} \mathrm{C}\right)$ artificial cerebral spinal fluid (aCSF) bubbled with $95 \% \mathrm{O}_{2}-5 \% \mathrm{CO}_{2}$. The composition of aCSF was (in mM): $124 \mathrm{NaCl}, 3 \mathrm{KCl}, 26 \mathrm{NaHCO}_{3}, 1.4 \mathrm{NaH}_{2} \mathrm{PO}_{4}, 11$ glucose, $1.3 \mathrm{CaCl}_{2}$, and $1.3 \mathrm{MgCl}_{2} ; \mathrm{pH}$ 7.3-7.4. The hypothalamus was blocked and glued onto a metal stage and $300 \mu \mathrm{m}$ slices were cut with a vibratome. The slices were transferred to a holding chamber and incubated in oxygenated aCSF at room temperature for $1 \mathrm{~h}$ before being transferred to a recording chamber mounted on the fixed stage of an upright microscope (BX51WI; Olympus, Melville, NY, USA).

\section{WHOLE-CELL RECORDINGS}

Whole-cell patch-clamp recordings were performed under visual control on an upright, fixed stage microscope equipped with infrared illumination and differential interference contrast (IRDIC) and epifluorescence illumination to identify EGFP-labeled cells (Olympus BX51WI). Epifluorescence was briefly used to target EGFP-labeled cells, at which time the light source was switched to IR-DIC to obtain the recording. Gastric-related preautonomic neurons were identified as EGFP-labeled as previously described (Smith et al., 2000; Glatzer et al., 2003) by visualization under fluorescence microscopy and were filled with biocytin during recordings for post hoc visualization with avidin-Texas Red.

For whole-cell patch-clamp recordings, electrodes (2-5M $\Omega$ ) were filled with a solution containing the following (in $\mathrm{mM}$ ): 130 $\mathrm{Cs}^{+}$-gluconate, $1 \mathrm{NaCl}, 5 \mathrm{EGTA}, 10 \mathrm{HEPES}, 1 \mathrm{MgCl}_{2}, 1 \mathrm{CaCl}_{2}$, 3 CsOH, 2-3 Mg-ATP, and 0.2\% biocytin, $\mathrm{pH}$ 7.3-7.4, adjusted with $5 \mathrm{M} \mathrm{CsOH}$. For current-clamp recordings, $\mathrm{K}^{+}$-gluconate was used in the recording pipette. To test whether these responses depended on G-protein activity in the recorded cell, a subset of neurons was recorded using pipettes containing guanosine $5^{\prime}[\beta$ thio]diphosphate trilithium salt (GDP $\beta$ S; $500 \mu \mathrm{M}$, Sigma-Aldrich, St. Louis, MO, USA). Excitatory postsynaptic currents (EPSCs) were examined at a holding potential of $-60 \mathrm{mV}$. Electrophysiological signals were recorded using an Axoclamp 700B amplifier (Molecular Devices, Union city, CA, USA), low-pass filtered at $2 \mathrm{kHz}$, and stored to a computer using a digidata 1440A A-D converter and pClamp 10.2 software (Molecular Devices, Union City, 
CA, USA). Synaptic currents were analyzed offline using pClamp 10.2 and MiniAnalysis 6.0.3. (Synaptosoft, Decatur, CA, USA).

\section{DRUG APPLICATION}

All experiments were performed with tetrodotoxin (TTX, $1 \mu \mathrm{M}$ ) in the aCSF solution to block action potentials and isolate mEPSCs, with the exception of on-cell recordings of firing activity. Dexamethasone (DEX, $10 \mu \mathrm{M}$; Sigma, St. Louis, MO, USA) and ruthenium red (RR, $1 \mu \mathrm{M}$; Tocris, Ellisville, MO, USA) were dissolved in aCSF; capsaicin $(\mathrm{CP}, 0.1,1,10 \mu \mathrm{M})$, capsazepine (CPZ, $10 \mu \mathrm{M}), 5^{\prime}$-iodoresiniferatoxin $\left(5^{\prime}\right.$-iRFT, $1 \mu \mathrm{M}$; Tocris Bioscience, Ellisville, MO, USA), and $4 \alpha$-phorbol 12,13-didecanoate (4- $\alpha$ PDD, $1 \mu \mathrm{M}$; Alexis Biochemicals, San Diego, CA, USA) were dissolved in ethanol and diluted in aCSF (final concentration of ethanol $<0.01 \%$ by volume). WIN 55,212-2 (10 $\mu \mathrm{M}$, Sigma), RN1743 (10 $\mu \mathrm{M}$; Tocris), and AM251 (10 $\mu \mathrm{M}$; Tocris) were dissolved in DMSO and diluted in aCSF. AEA $(10 \mu \mathrm{M})$ was purchased as predissolved stock in Tocrisolve (Tocris). Vehicle alone had no effect on membrane or synaptic properties (Derbenev et al., 2006).

\section{DATA ANALYSIS}

Baseline (control) mean frequency and amplitude of mEPSCs were obtained over a 3 min period just prior to drug application. Measurements of drug effects within a given recording were assessed from the average of the first 3 min after drug application (i.e., 0-3 min after the drug equilibrated in the recording chamber; i.e., 3 min time point) and during $\min 6-9$ (i.e., 9 min time point) of drug application. The effect of agonists and antagonists on mEPSC frequency and amplitude were analyzed using a repeated-measures ANOVA comparing control to segments examined 0-3 and 6-9 min after agonist application. When appropriate, Tukey's post hoc test was used to determine significance. The nonparametric, intra-assay Kolmogorov-Smirnov test (K-S test; > 150 events per condition) was also used initially to objectively determine if a given cell demonstrated a change in mEPSC frequency or amplitude during the first $3 \mathrm{~min}$ of drug application. A probability of $<0.02$ was considered significant for $\mathrm{K}-\mathrm{S}$ analyses. In the population in which it was detected, the magnitude of change was assessed using a paired one-tailed Student's $t$-test, where indicated. All other comparisons of single-variable grouped data were performed using paired, two-tailed Student's $t$-test. Probability values $<0.05$ were considered significant for grouped data. Values are reported as the mean \pm SEM.

\section{RESULTS \\ IDENTIFICATION AND MEMBRANE PROPERTIES OF GASTRIC-RELATED PRV-152-LABELED NEURONS}

Expression of EGFP in PVN neurons was observed beginning $72 \mathrm{~h}$ after PRV-152 inoculation of the stomach. Gastric-related preautonomic neurons labeled with EGFP were targeted for recording 72-96 h after inoculation (Figures 1A-E), a time window during which the electrophysiological properties of PRV-152-infected neurons were demonstrated previously to be unaffected by the virus (Smith et al., 2000; Glatzer et al., 2003, 2007). To confirm their identity as EGFP-labeled, gastric-related neurons and their location in PVN, a subset of recorded neurons was filled with biocytin and visualized post hoc with an avidin-Texas Red or avidinrhodamine conjugate and/or an $\mathrm{ABC}-\mathrm{DAB}$ reaction (Figure 1).
Action potential firing and membrane properties of EGFP-labeled PVN neurons (Figures 1F,G) were examined and were found to be similar to those reported previously for PVN preautonomic neurons (Stern, 2001; Luther et al., 2002). Electrophysiological characteristics of gastric-related preautonomic PVN neurons included four basic firing patterns, including tonic regular, tonic irregular, bursting, and silent (Figure 1F, silent cells not presented), consistent with previous analyses of retrogradely labeled preautonomic and neuroendocrine PVN neurons (Stern, 2001; Luther et al., 2002). The presence of low-threshold spikes in response to depolarizing current pulses (70-90 pA) from a hyperpolarized membrane potential $(-80$ to $-90 \mathrm{mV})$ was also observed, suggesting the activation of low-voltage activated calcium channels (Figure 1G).

\section{BIPHASIC EFFECT OF DEX ON mEPSC FREQUENCY}

Glucocorticoids were recently demonstrated to induce the retrograde release of eCBs from magnocellular and parvocellular neuroendocrine PVN neurons, leading to a presynaptic, CB1Rmediated reduction in mEPSC frequency within minutes of drug application (Di et al., 2003, 2005b). Here, mEPSCs were recorded to investigate the rapid effect of the synthetic glucocorticoid dexamethasone (DEX) on spike-independent glutamate release onto gastric-related preautonomic PVN neurons. Gastric-related preautonomic parvocellular PVN neurons demonstrated a significant decrease in mEPSC by 9 min of DEX application (Tukey's; $p=0.0008 ; n=11$; Figure 2). Under control conditions, the average mEPSC frequency for all cells was $3.1 \pm 0.8 \mathrm{~Hz}(n=11)$ and ranged from 1.2 to $11.0 \mathrm{~Hz}$. After $10 \mu \mathrm{M}$ DEX application, the mean frequency of mEPSCs was decreased to $2.1 \pm 0.6 \mathrm{~Hz}$ (range $0.7-7.4 \mathrm{~Hz}$ ). The decrease in frequency at $9 \mathrm{~min}$ was detected in each of the 11 neurons. However, we also examined individual responses from 15 neurons during the first 3 min of DEX application and determined that $40 \%$ of the gastric-related preautonomic PVN neurons exhibited a significant increase in mEPSC frequency shortly after agonist application ( $\mathrm{K}-\mathrm{S}$ test; $p<0.02)$. Thus, in 6 out of 15 gastric-related preautonomic cells (40\%), DEX-induced a rapid and transient increase in the mEPSC frequency within the first $3 \mathrm{~min}$ of drug exposure. Under control conditions, the average mEPSC frequency in these six neurons was $1.3 \pm 0.2 \mathrm{~Hz}$ (range $0.9-1.8 \mathrm{~Hz}$ ). The mean mEPSC frequency over the first 3 min DEX application $(10 \mu \mathrm{M})$ increased to $2.0 \pm 0.2 \mathrm{~Hz}$ (range 1.2-2.4 Hz; $p<0.05$; paired $t$-test; $n=6$; Figure 2). There was no correlation between the control mEPSC frequency in a given cell and the relative change in frequency subsequent to DEX application at either the $3 \mathrm{~min}(R=0.0006)$ or $9 \min (R=0.0604)$ time points. There was no significant change in mEPSC amplitude during DEX application; the average amplitude before application of DEX was $11.5 \pm 1 \mathrm{pA}$ and after bath application of DEX was $10.4 \pm 1 \mathrm{pA}(n=11 ; p>0.05)$. Thus, whereas DEX application reduced mEPSC frequency in all neurons tested, this reduction was preceded by a transient enhancement in frequency in a large subset of neurons. In five neurons, mEPSC frequency was also examined 12-15 min after returning to normal ACSF to determine if the changes in mEPSC frequency were reversible. Return of mEPSC frequency to control levels $15 \mathrm{~min}$ after DEX application was apparent in only one cell, so recovery was not further examined. 

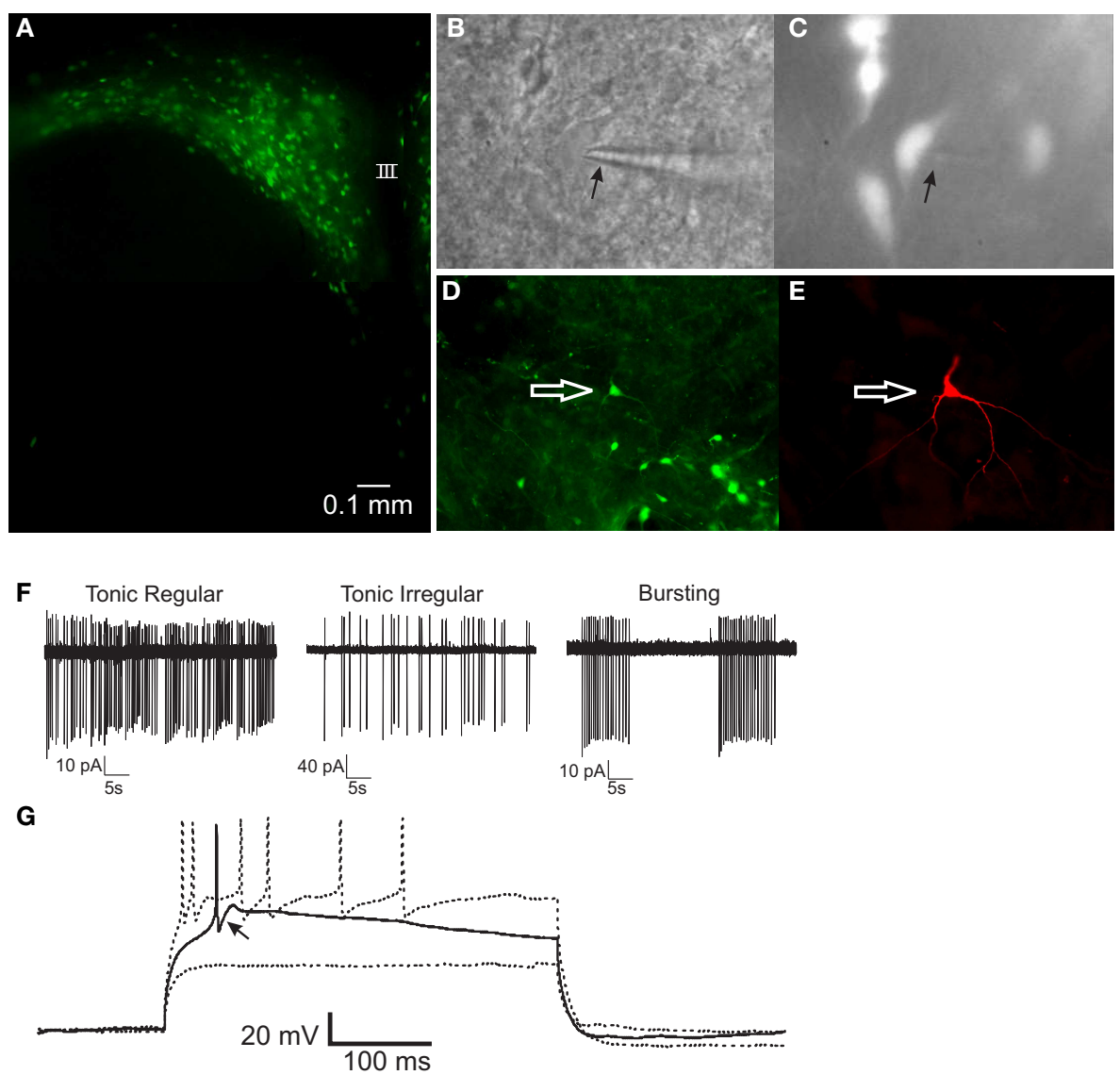

FIGURE 1 | PRV-152-infected gastric-related preautonomic neuron recorded in the PVN. (A) Fluorescence micrograph of a PVN slice $(300 \mu \mathrm{m})$ showing EGFP-labeled, gastric-related preautonomic neurons approximately $90 \mathrm{~h}$ after PRV-152 inoculation of the stomach. (B) Example of a PVN neuron that was recorded in the slice preparation. Arrow indicates to recording pipette. (C) The same neuron as in (B) illuminated with epifluorescence indicating it contained GFP. (D) Image of a slice from which a GFP-labeled PVN neuron was recorded. The arrow indicates the recorded cell. (E)
Fluorescence image of the recorded cell [same as in (D)] filled with biocytin and visualized with an Avidin-Texas Red conjugate. (F) Loose-patch recordings of action potential activity demonstrating typical firing patterns in three PRV-152 labeled, gastric-related PVN neurons. (G) Current-clamp recording from a gastric-related preautonomic neuron that generated a low-threshold spike (arrow) in response to depolarizing current pulses (70-90 pA) from a membrane potential of $-90 \mathrm{mV}$ [same neuron as shown in (D,E)]. III, third ventricle.

\section{BIPHASIC EFFECT OF ANANDAMIDE ON mEPSC FREQUENCY}

The effects of eCB agonists have been shown to involve cannabinoid (Di et al., 2003, 2005b) and/or vanilloid receptor activation (Derbenev et al., 2004, 2006) when these receptors are present centrally. Since the rapid glucocorticoid actions on glutamate release onto PVN neuroendocrine cells are mediated by eCB synthesis and retrograde release (Di et al., 2003, 2005b), we tested for the eCBdependence of the biphasic DEX modulation of mEPSC frequency in gastric-related preautonomic PVN neurons. Similar to the DEX effect, bath application of $10 \mu \mathrm{M}$ AEA biphasically altered mEPSC frequency (Figure 3). In the presence of AEA, all observed PVN cells demonstrated a decrease in mEPSC frequency by 9 min compared to both control and $3 \mathrm{~min}$ as determined by a Tukey's post hoc $(n=9 ; p<0.0001)$. The frequency of mEPSCs in control conditions for all neurons tested was $4.9 \pm 0.7 \mathrm{~Hz}$ (range $1.5-8.1 \mathrm{~Hz}$; $n=9)$. After a 9 min application of AEA $(10 \mu \mathrm{M})$, the mEPSC frequency decreased to $3.4 \pm 0.6 \mathrm{~Hz}$ (range $0.8-6.3 \mathrm{~Hz} ; p<0.001$; Tukey's; Figure 3E), which was similar to the inhibition of mEPSCs reported in PVN parvocellular and magnocellular neuroendocrine cells (Di et al., 2003, 2005b). Responses to AEA application within 11 individual cells revealed a subset of PVN neurons that demonstrated a rapid increase in mEPSC frequency $(p<0.02)$. The rapid, transient increase in mEPSC frequency was observed in 5 out of 11 gastric-related preautonomic cells $(45 \%)$ in the first $3 \mathrm{~min}$ of the drug application (Figure 3 ). The average basal mEPSC frequency in these cells was $3.8 \pm 1.2 \mathrm{~Hz}$ (range $0.8-7.6 \mathrm{~Hz}$ ). After application of AEA $(10 \mu \mathrm{M})$, the mean frequency of mEPSCs was increased to $5.2 \pm 1.0 \mathrm{~Hz}$ (range $2.5-8.4 \mathrm{~Hz} ; n=5 ; p<0.03$; paired one-tailed $t$-test). There was no significant change in the mEPSC amplitude after application of AEA. The average amplitude before application of AEA was $14 \pm 1 \mathrm{pA}$ (range 9-19pA; $n=11$ ) and after 9 min application of AEA was $13.7 \pm 1.2 \mathrm{pA}$ (range $7-19 \mathrm{pA}$; $p>0.05)$. There was no correlation between the control mEPSC frequency in a given cell and the relative increase in frequency subsequent to AEA application at either the $3(R=0.1076)$ or $9 \mathrm{~min}$ $(R=0.1709)$ time points. The frequency of mEPSCs was therefore 

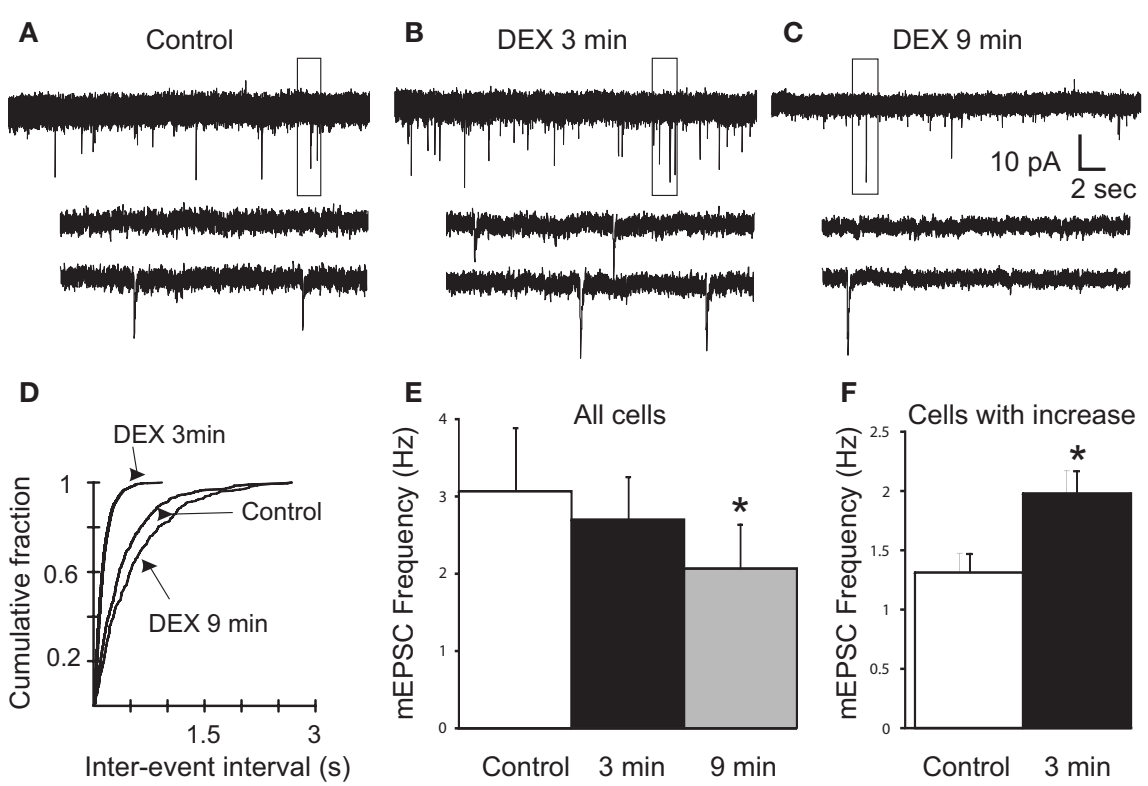

FIGURE 2 | Rapid biphasic changes in mEPSC frequency in PVN gastric-related preautonomic neurons elicited by dexamethasone (DEX). (A-C) Sequential recordings of mEPSCs observed in an EGFP-labeled PVN neuron at a holding potential of $-60 \mathrm{mV}$ in control conditions (A) and after $3 \mathrm{~min}$ (B) and $9 \mathrm{~min}$ (C) of bath application of $10 \mu \mathrm{M}$ DEX. Bottom traces show the boxed areas in the upper traces on an expanded time scale. (D) Cumulative probability plots of inter-mEPSC interval distribution from the same cell showed a significant increase at 3 min (leftward shift) and a significant decrease at 9 min (rightward shift) in mEPSC frequency (K-S test, $p<0.02$ ). (E) Mean group changes in mEPSC frequency caused by $10 \mu \mathrm{M}$ DEX at 3 and $9 \mathrm{~min}$ ( $n=11$; ANOVA, Tukey's; ${ }^{*} p<0.05$ from control). (F) Mean group frequency changes in the subset of neurons in which the K-S test detected an increase in mEPSC frequency $\left(n=6 ;{ }^{*} p<0.05, t\right.$-test).
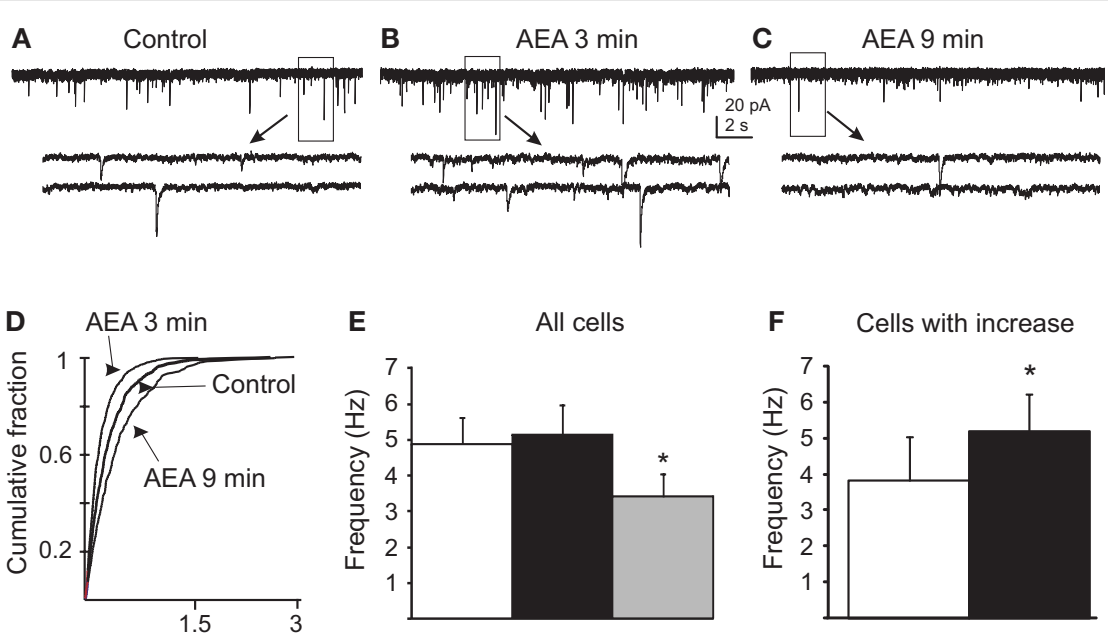

Inter-event interval (s)
$\mathbf{E}$

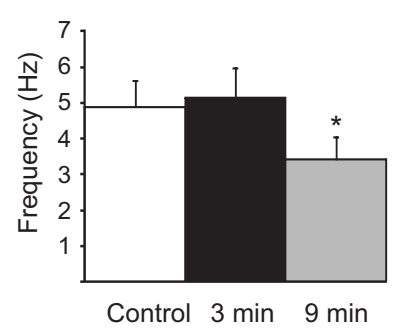

F

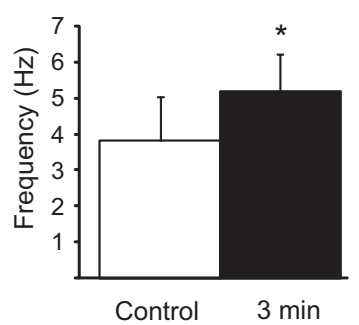

FIGURE 3 | Anandamide biphasically altered mEPSC frequency in gastric-related preautonomic neurons. (A-C) Sequential recordings of mEPSCs observed in EGFP-labeled PVN neurons at a holding potential of $-60 \mathrm{mV}$ in control conditions (A) and after $3 \mathrm{~min}$ (B) and $9 \mathrm{~min}$ (C) of bath application of $10 \mu \mathrm{M}$ AEA. Bottom traces show the boxed areas in the upper traces on an expanded time scale. (D) Cumulative probability plots of inter-mEPSC interval distribution from the same cell showed a significant increase at 3 min (leftward shift) and a significant decrease at 9 min (rightward shift) in mEPSC frequency ( $p<0.02 ; \mathrm{K}-\mathrm{S}$ test). (E) Pooled data from all tested cells showing changes in frequency of mEPSCs caused by $10 \mu \mathrm{M}$ AEA at 3 and $9 \mathrm{~min}$ ( $n=9$; ${ }^{*} p<0.05$ from control and $3 \mathrm{~min}$; ANOVA, Tukey's). (F) Pooled data from the subset of neurons that responded to AEA with an increase in mEPSC frequency $(45 \%)$ showing changes in the frequency of $\operatorname{mEPSC}$ at $3 \min \left(n=5 ;{ }^{*} p<0.05, t\right.$-test). biphasically altered by AEA in a subset of neurons, but the overall effect was a decrease in mEPSC frequency by $9 \mathrm{~min}$ of AEA application.

\section{CB1 RECEPTOR DEPENDENCE OF DEX AND AEA EFFECT}

To determine if $\mathrm{CB} 1$ receptors participated in the DEX and AEA inhibition of mEPSC frequency, DEX and AEA were applied in the 
presence of the CB1R antagonist AM251 $(10 \mu \mathrm{M})$. The mEPSC frequency was unaffected by AM251 alone, but the decrease in mEPSC frequency induced by $\operatorname{DEX}(10 \mu \mathrm{M})$ or AEA $(10 \mu \mathrm{M})$ at $10 \mathrm{~min}$ was prevented by the antagonist. In the presence of AM251, a rapid increase in mEPSC frequency was observed after application of DEX or AEA. Bath application of $10 \mu \mathrm{M}$ DEX in the presence of AM251 increased mEPSC frequency from $6.6 \pm 2.1 \mathrm{~Hz}$ (range 2.9-12.2 Hz) to $8.7 \pm 2.6 \mathrm{~Hz}$ (range $4.4-15.4 \mathrm{~Hz} ; p<0.05$; paired $t$-test) in four out of seven cells during the first $3 \mathrm{~min}$ (57\%; Figure 4B), while the mEPSC frequency in the remaining three cells was unaffected. However, no cell demonstrated a decrease in mEPSC frequency at either early or later time periods (Tukey's, $p=0.12$; Figure 4A). Similarly, bath application of $10 \mu \mathrm{M}$ AEA in the presence of AM251 increased mEPSC frequency from $2.8 \pm 0.6 \mathrm{~Hz}$ (range $2.0-4.1 \mathrm{~Hz}$ ) to $4.3 \pm 0.6 \mathrm{~Hz}$ (range 3.6$5.7 \mathrm{~Hz} ; p<0.02$; paired $t$-test) in three out of seven cells $(43 \%)$, but a decrease in mEPSC frequency was not detected during AEA application (Tukey's, $p=0.58$ ). Whereas the decrease in mEPSC frequency was blocked by the $\mathrm{CB} 1$ receptor antagonist, the transient increase in mEPSC frequency caused by DEX or AEA in a subset of neurons was not prevented.

The high-affinity synthetic cannabinoid agonist WIN 55,212-2 (WIN) decreased the mEPSC frequency in preautonomic parvocellular neurons. The $\mathrm{K}-\mathrm{S}$ test did not detect a subset of neurons in which mEPSC frequency increased. Rather bath application of $10 \mu \mathrm{M}$ WIN decreased mEPSC frequency in all cells tested measured by $9 \mathrm{~min}$ from $1.1 \pm 0.3 \mathrm{~Hz}$ (range 0.4$3.4 \mathrm{~Hz}$ ) to $0.6 \pm 0.2 \mathrm{~Hz}$ (range $0.4-1.8 \mathrm{~Hz} ; p<0.04$; Tukeys; $n=8$; Figure 4C); there was no change in frequency in any recording at the earlier time point $(p>0.05)$. The inhibitory effect of DEX on mEPSC frequency was thus prevented by a CB1 receptor antagonist and mimicked by a CB receptor agonist. It was likely mediated, therefore, by the release of an $\mathrm{eCB}$, similar to the effect described previously in PVN neuroendocrine cells (Di et al., 2003, 2005b).

\section{TRP RECEPTOR DEPENDENCE OF DEX AND AEA EFFECT}

Anandamide is an agonist at TRPV1 (Di Marzo et al., 1994; Zygmunt et al., 1999) and effects of the TRPV1 agonist capsaicin have been reported previously in parvocellular PVN cells ( $\mathrm{Li}$ et al., 2004). We hypothesized that the DEX- and AEA-induced transient increases in mEPSC frequency in preautonomic neurons were caused by the activation of TRPV receptors in the PVN. To determine if the rapid, transient increase in mEPSC frequency could be mimicked by a TRPV1 agonist other than AEA, the effect of capsaicin was investigated in PRV-152 labeled, gastric-related, preautonomic PVN neurons. Within 3 min of application, capsaicin increased the frequency of mEPSCs in EGFP-labeled preautonomic neurons. Bath application of $100 \mathrm{nM}$ capsaicin increased mEPSC frequency in one neuron (i.e., by $\mathrm{K}-\mathrm{S}$ test) but had no significant overall effect on the mEPSC frequency. Baseline frequency was $3.5 \pm 0.9 \mathrm{~Hz}$ (range $0.8-4.9 \mathrm{~Hz}$ ) and was $3.8 \pm 1.0 \mathrm{~Hz}$ in $100 \mathrm{nM}$ capsaicin (range $0.8-5.4 \mathrm{~Hz} ; p>0.05$; two-tailed, paired $t$-test; $n=4)$. Application of $1 \mu \mathrm{M}$ capsaicin increased significantly the frequency of mEPSCs in four of five neurons. Mean frequency was increased significantly in this group of cells, from $3.3 \pm 1.0 \mathrm{~Hz}$ (range $1.3-6.5 \mathrm{~Hz}$ ) to $5.2 \pm 0.9 \mathrm{~Hz}$ (range $3.0-7.9 \mathrm{~Hz}$; $p<0.05 ; n=5)$. Application of $10 \mu \mathrm{M}$ capsaicin increased mEPSC frequency in seven of eight neurons. Mean frequency was increased from $4.5 \pm 1.1 \mathrm{~Hz}$ (range $0.8-7.7 \mathrm{~Hz}$ ) to $8.3 \pm 1.8 \mathrm{~Hz}$ (range 0.9 $13.5 \mathrm{~Hz} ; p<0.05 ; n=8$ ). There was no correlation between the control mEPSC frequency in a given cell and the relative increase in frequency subsequent to capsaicin application $(R=0.1416)$. There was no significant change in mEPSC amplitude after application of any concentration of capsaicin $(p>0.05)$.

Application of the broad-spectrum TRPV antagonist ruthenium red $(1 \mu \mathrm{M})$ blocked completely the rapid increase in mEPSC frequency caused by DEX ( $10 \mu \mathrm{M} ; n=5)$, capsaicin $(1 \mu \mathrm{M} ; n=5)$ and AEA $(10 \mu \mathrm{M}, n=8$; Table 1$)$ in gastric-related PVN neurons. In the presence of ruthenium red, DEX $(10 \mu \mathrm{M})$ induced a $15 \pm 6 \%$ decrease in mEPSC frequency instead of an increase at $3 \mathrm{~min}$ (compare to $53 \pm 10 \%$ increase, Figure $2 \mathrm{~F}$ ), which then progressed to a $37 \pm 6 \%$ decrease in mEPSC frequency by $9 \mathrm{~min}$ $(p<0.05$; ANOVA, Tukey's; $n=5)$; the decrease in mEPSC frequency at 9 min was similar to that seen in the absence of ruthenium red. Application of capsaicin $(1 \mu \mathrm{M})$ was without effect in the presence of ruthenium red $(p>0.05 ; n=5$; Table 1$)$.
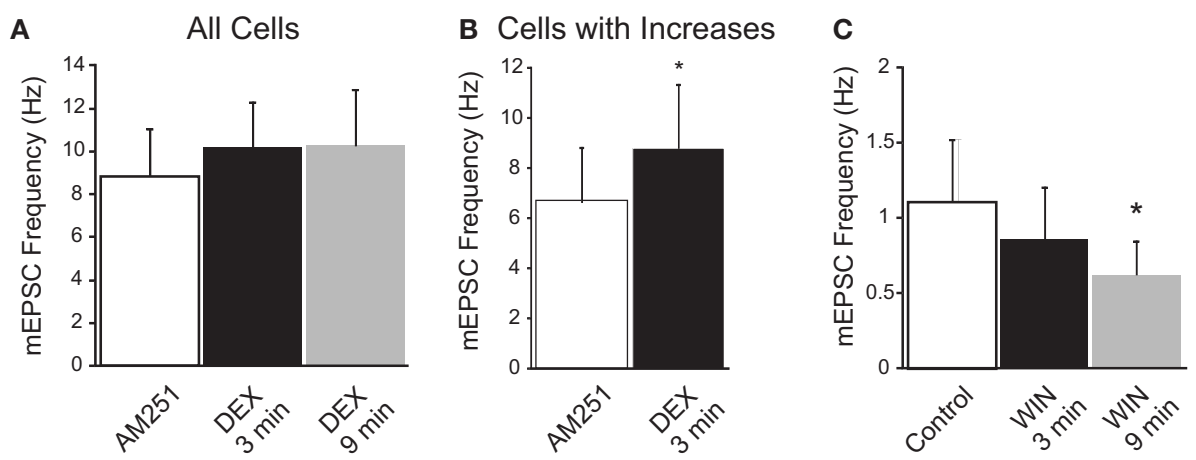

FIGURE 4 | CB1 receptor dependence of dexamethasone (DEX)-induced suppression of $\mathbf{m E P S C}$ frequency. $(\mathbf{A})$ In the presence of the CB1 receptor antagonist (AM251; $10 \mu \mathrm{M})$, DEX did not elicit a significant decrease in mEPSC frequency ( $n=6$; ANOVA, Tukey's). (B) In AM251, DEX increased $m E P S C$ frequency in a subset of neurons. The graph illustrates the mean frequency change in cells in which an increase in mEPSC frequency was detected ( $n=4 ;{ }^{*} p<0.05$, $t$-test). (C) The synthetic cannabinoid agonist, WIN $55,212-2(\mathrm{WIN} ; 10 \mu \mathrm{M})$ decreased the frequency of mEPSCs $\left(n=8 ;{ }^{*} p<0.05\right.$ from control; ANOVA, Tukey's); an increase in mEPSC frequency was not observed at either the early or late time point in the presence of WIN. 
Table 1 | Percent of cells responding with an increase in mEPSC frequency and percent frequency change due to DEX, AEA, and capsaicin after TRPV receptor block.

\begin{tabular}{|c|c|c|c|c|c|c|}
\hline & \multicolumn{2}{|c|}{ DEX $(10 \mu M)$} & \multicolumn{2}{|c|}{ AEA $(10 \mu M)$} & \multicolumn{2}{|c|}{ Capsaicin $(1 \mu M)$} \\
\hline & $\begin{array}{l}\% \text { Responding } \\
\text { cells }\end{array}$ & $\begin{array}{l}\% \text { Frequency } \\
\text { change }\end{array}$ & $\begin{array}{l}\% \text { Responding } \\
\text { cells }\end{array}$ & $\begin{array}{l}\% \text { Frequency } \\
\text { change }\end{array}$ & $\begin{array}{l}\% \text { Responding } \\
\text { cells }\end{array}$ & $\begin{array}{l}\% \text { Frequency } \\
\text { change }\end{array}$ \\
\hline Control & $40(15)$ & $53 \pm 10$ & $45(11)$ & $103 \pm 72$ & $80(5)$ & $113 \pm 39$ \\
\hline TRPV1 KO & - & - & - & - & $57(7)$ & $36 \pm 18$ \\
\hline TRVP1 antagonist & $40(10)$ & $32 \pm 13$ & $50(10)$ & $62 \pm 34$ & $64(14)$ & $92 \pm 33$ \\
\hline
\end{tabular}

Numbers in parenthesis indicate total number of cells examined. AEA, anandamide; DEX, dexamethasone.

Ruthenium red prevented the rapid increase in mEPSC frequency by AEA in the first 3 min (Table 1), but did not affect the decrease in $\mathrm{mEPSC}$ frequency at $9 \min (32 \pm 9 \% ; p<0.05, n=6)$. Ruthenium red $(1 \mu \mathrm{M})$ alone had no effect on the baseline frequency of mEPSCs in any of four cells tested. It prevented the rapid, transient increase in mEPSC frequency caused by DEX, capsaicin, and AEA, whereas the later inhibition of mEPSCs by DEX and AEA was not blocked. These data implicated the involvement of a receptor from the TRPV family in the excitatory effect of DEX and AEA on mEPSC frequency (Table $\mathbf{1}$ ).

To identify the possible receptor(s) mediating the rapid facilitatory effect of AEA, DEX, and capsaicin on mEPSC frequency, selective antagonists to TRPV1 were applied prior to application of capsaicin $(1 \mu \mathrm{M})$, AEA $(10 \mu \mathrm{M})$, and DEX $(10 \mu \mathrm{M})$. A $15 \mathrm{~min}$ preapplication of neither the selective TRPV1 receptor antagonist capsazepine $(10 \mu \mathrm{M})$ nor the potent TRPV1 antagonist $5^{\prime}$-iRFT $(1 \mu \mathrm{M})$ blocked completely the excitatory effect of capsaicin, AEA, or DEX. The K-S test revealed a significant capsaicin-mediated increase in mEPSC frequency in four out of seven cells in the presence of $5^{\prime}$-iRFT $(p<0.05$; Table 1$)$. An increase in mEPSC frequency $(62 \pm 34 \%)$ induced by AEA $(10 \mu \mathrm{M})$ was also seen in 5 of 10 cells in the presence of $5^{\prime}$-iRFT $(p<0.05)$. In addition, DEX $(10 \mu \mathrm{M})$ increased mEPSC frequency $(32 \pm 13 \%)$ in 4 of 10 cells in the presence of capsazepine $(10 \mu \mathrm{M}, p<0.05$; K-S test; Table 1$)$, while capsaicin $(1 \mu \mathrm{M})$ increased mEPSC frequency in five of seven cells (Table 1). The percentage of neurons that responded to AEA and DEX application was similar in control conditions $(\sim 50 \%)$ and in the presence of TRPV1 antagonist ( $\sim 50 \%)$, but the magnitude of the increase observed under control conditions $(53 \pm 10 \%$ for DEX; $102 \pm 78 \%$ for AEA) was greater than that observed in the presence of the antagonist $(32 \pm 13 \%$ for DEX; $62 \pm 34 \%$ for AEA), suggesting that a portion $(\sim 50 \%)$ of the agonist activity was due to activation of TRPV1 (Table 1). In addition to capsaicin-induced TRPV1-mediated effects in PVN (Li et al., 2004), a non-TRPV1-mediated increase in mEPSC frequency was also elicited by capsaicin, AEA, and DEX when TRPV1 receptors were blocked.

\section{TRPV1 KNOCKOUT MICE}

To verify that the capsaicin-mediated increase in mEPSC frequency was mediated by receptors other than TRPV1 and was not simply a result of agonists "outcompeting" antagonists, we determined the effect of capsaicin on mEPSCs in gastric-related PVN neurons in slices from TRPV1 knockout mice $\left(B 6.129 \times 1-\operatorname{Trpv} 1^{\mathrm{tm} 1 J u l} / \mathrm{J}\right.$ homozygote). Absence of the nociceptive wiping response to ocular application of a capsaicin solution $(200 \mu \mathrm{M})$ was used to verify the absence of TRPV1 functionality in the knockout mice (Gamse, 1982). Bath application of capsaicin $(1 \mu \mathrm{M})$ significantly increased the frequency of mEPSCs in four out of seven cells from TRPV1 knockout mice within 3 min of application, from $2.9 \pm 0.8 \mathrm{~Hz}$ (range $1.6-5.2 \mathrm{~Hz}$ ) in control to $3.8 \pm 0.8 \mathrm{~Hz}$ in capsaicin (range 2.4-5.8 Hz; $p<0.05 ; n=4$; Table 1 ).

Dexamethasone application resulted in a ruthenium redsensitive enhancement of mEPSC frequency that was reduced, but was not blocked by selective TRPV1 antagonists. To determine if the DEX-induced changes in mEPSC frequency involved activation of TRPV4 in addition to TRPV1 and CB1 receptors, DEX was applied in the presence of a cocktail of AM251 $(10 \mu \mathrm{M})$, $5^{\prime}$-iRFT $(10 \mu \mathrm{M})$, and the TRPV4 antagonist RN $1734(10 \mu \mathrm{M})$. In the presence of these combined selective antagonists, baseline mEPSC frequency was $5.3 \pm 1.0 \mathrm{~Hz}(n=5)$. DEX application failed to increase mEPSC frequency at $3 \mathrm{~min}(5.5 \pm 1.1 \mathrm{~Hz}$; $p>0.05)$ or decrease mEPSC frequency at $9 \min (5.9 \pm 1.2 \mathrm{~Hz}$; $p>0.05$; Table 1; Figure 5) in any neuron in the presence of the antagonists. Although a residual increase in mEPSC frequency was observed after TRPV1/CB1 receptor blockade alone, addition of a TRPV4 antagonist completely prevented the effects of DEX on mEPSC frequency.

\section{THE EFFECT OF TRPV4 AGONIST}

Recent evidence suggests that AEA may modulate TRPV4 activity in addition to TRPV1 and CB1R (Watanabe et al., 2003; Nilius et al., 2007). Because TRPV1 and TRPV4 have similar functional and pharmacological properties and are often co-expressed in the same brain regions (Cohen, 2007; Nilius et al., 2007), we examined TRPV4 activation by $4-\alpha-P D D$ in gastric-related preautonomic PVN neurons of rats and TRPV1 knockout mice to verify the presence of functional TRPV4 receptors in these animals. In rats, bath application of $4-\alpha-P D D(1 \mu \mathrm{M})$ increased mEPSC frequency in each of four cells, from $2.8 \pm 0.5 \mathrm{~Hz}$ in control (range 1.6-4.3 Hz) to $3.5 \pm 0.6 \mathrm{~Hz}$ in $4-\alpha-\mathrm{PDD}$ (range $2.2-5.1 \mathrm{~Hz}, p<0.05, n=4$ ) at $3 \mathrm{~min}$ (Figure 5G). In TRPV1 knockout mice, bath application of 4 - $\alpha$-PDD $(1 \mu \mathrm{M})$ increased mEPSC frequency in each of six neurons, from $3.1 \pm 1 \mathrm{~Hz}$ (range $0.3-6.3 \mathrm{~Hz}$ ) to $4.2 \pm 1.3 \mathrm{~Hz}$ 


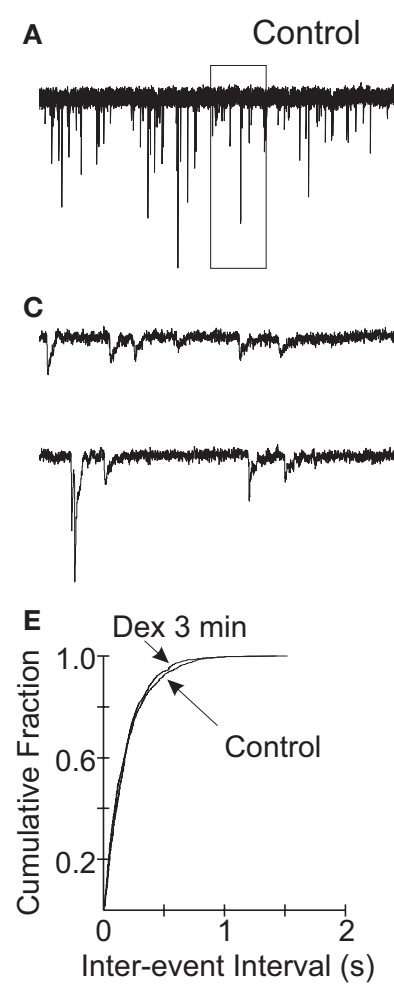

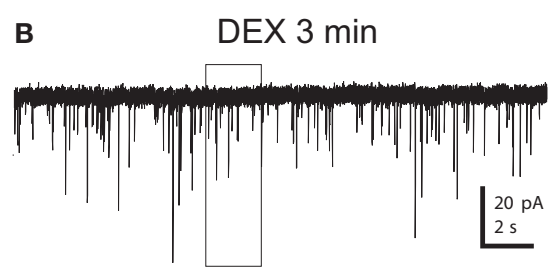

D

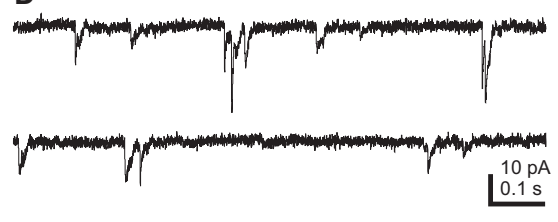

$\mathbf{F}$

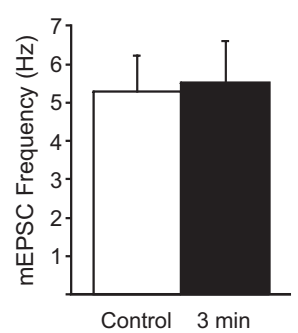

G

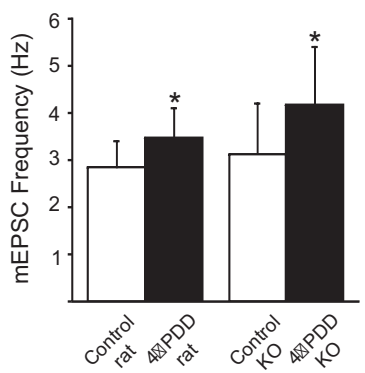

FIGURE 5 | Rapid increase in mEPSC frequency in PVN gastric-related preautonomic neurons elicited by dexamethasone (DEX) at $3 \mathrm{~min}$ depends on TRPV1 and TRPV4 receptors. $(A, B)$ Sequential recordings of mEPSCs observed in an EGFP-labeled PVN neuron at a holding potential of $-60 \mathrm{mV}$ in the presence of AM251 and the selective TRPV1 (5'-iRFT) and TRPV4 (RN1734) antagonists during control conditions (A) and after $3 \mathrm{~min}$ (B) of bath application of $10 \mu \mathrm{M}$ DEX. (C,D) Expanded traces from the boxed areas in the traces shown in (A,B). (E) Cumulative probability plots of inter-mEPSC interval distribution from the same cell showed no significant increase at $3 \mathrm{~min}$ in $\mathrm{mEPSC}$ frequency ( $p<0.02 ; \mathrm{K}-\mathrm{S}$ test). (F) No change in group means in mEPSC frequency after by $10 \mu \mathrm{M}$ DEX at 3 and $9 \min (n=5$; $p>0.05$; ANOVA, Tukey's). (G) 4- $\alpha$-PDD $(1 \mu \mathrm{M})$, a selective TRPV4 receptor agonist, increased the mEPSC frequency in gastric-related preautonomic PVN neurons from rat $(n=4)$ and TRPV1 knockout mice $(n=6 ; p<0.05$; $t$-test). (range $0.6-8.3 \mathrm{~Hz}, p<0.05 ; n=6$ ) by $3 \mathrm{~min}$ of drug application (Figure 5G). Like activation of TRPV1 receptors, activation of TRPV4 receptors also produced an increase in mEPSC frequency in gastric-related PVN neurons.

\section{EFFECT OF DEX ON mEPSC FREQUENCY DEPENDS ON G-PROTEIN-MEDIATED ACTIVITY}

It was shown previously that DEX-induced eCB-mediated effects on synaptic input via a postsynaptic, G-protein-dependent effect in PVN neurons (Di et al., 2003, 2009). To determine if the effect of DEX on mEPSC frequency depended on G-proteinmediated activity in the recorded gastric-related neurons, cells were loaded intracellularly with GDP- $\beta-S(500 \mu \mathrm{M})$ to inhibit G-protein function. The frequency of mEPSCs was $1.9 \pm 0.4 \mathrm{~Hz}$ in five cells loaded with GDP- $\beta-S$ (Figure 6). Application of $\operatorname{DEX}(10 \mu \mathrm{M})$ failed to alter mEPSC frequency in any neuron either during the first $3 \mathrm{~min}(1.8 \pm 0.4 \mathrm{~Hz} ; p>0.05)$ or at $9 \min (1.9 \pm 0.4 \mathrm{~Hz} ; p>0.05)$, as determined by either the intraassay $\mathrm{K}-\mathrm{S}$ test or repeated-measures ANOVA. Blocking G-protein activity in recorded neurons with intracellular GDP- $\beta-S$, therefore, prevented the rapid excitatory and inhibitory effects of DEX.

\section{DISCUSSION}

In this study we present evidence for a novel rapid biphasic modulation by glucocorticoids and AEA of excitatory synaptic input to a subset of identified gastric-related preautonomic neurons in the PVN of the rat hypothalamus. This modulation occurs via dual activation of TRPV and CB1 receptors in a subset of neurons. To target the stomach-related preautonomic PVN neurons specifically, we used the transsynaptic retrograde transport of PRV-152, which expressed EGFP in pre-gastric neurons. Organspecific labeling with PRV-152 after peripheral inoculation has been demonstrated previously (Larsen, 1999; Cano et al., 2000, 2001; Glatzer et al., 2003; Williams et al., 2007). Consistent with previous findings (Smith et al., 2000; Irnaten et al., 2001; Davis et al., 2003; Glatzer et al., 2003, 2007; Derbenev et al., 2004; Williams and Smith, 2006), we did not observe any obvious differences in the basic electrophysiological properties of PRV152-labeled neurons versus those reported for preautonomic PVN neurons identified by other methods, including the presence of low-threshold spikes that characterize these neurons (Stern, 2001; Luther et al., 2002). Recorded PVN neurons expressing EGFP were, therefore, likely to be preautonomic cells with polysynaptic projections to the stomach. 


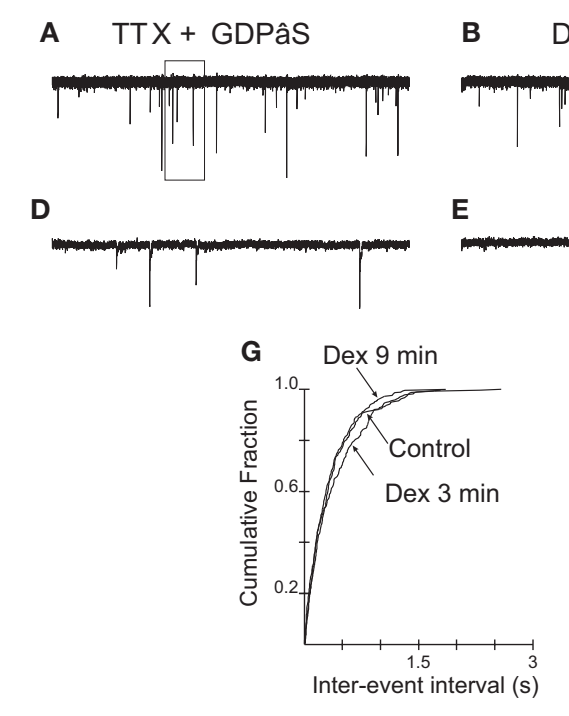

FIGURE 6 | Blockade of G-protein activity prevented DEX-induced changes in $\mathrm{mEPSC}$ frequency in PVN gastric-related preautonomic neurons. (A-C) Sequential recordings of mEPSCs observed in an EGFP-labeled PVN neuron at a holding potential of $-60 \mathrm{mV}$ loaded with the G-protein inhibitor, GDP $\beta$ S, during control conditions (A), after 3 (B) and $9 \mathrm{~min}$ (C) of bath application of $10 \mu \mathrm{M}$ DEX. (D-F) Expanded traces

\section{ACTIVATION OF CB1 RECEPTORS}

Previous data indicated that DEX activates a postsynaptic membrane-associated receptor in PVN neurosecretory neurons, which leads to the release of the eCBs, AEA, and 2-AG (Di et al., 2003, 2005a; Evanson et al., 2010). Immunohistochemical evidence indicates the presence of CB1R in the PVN (Cristino et al., 2006). We observed a significant inhibition of glutamate release in gastric-related preautonomic PVN neurons, as indicated by a decrease in mEPSC frequency by 9 min of DEX application. This was mimicked within a similar time frame by AEA and WIN 55,212-2 and was abolished by the CB1 receptor antagonist AM251. This finding is similar to observations in neuroendocrine parvocellular and magnocellular PVN cells, where glucocorticoids and cannabinoid agonists inhibited glutamatergic input to neuroendocrine cells (Di et al., 2003, 2005a). The inhibition of mEPSC frequency was likely mediated by $\mathrm{CB} 1$ receptor activation, as previously reported for neuroendocrine neurons of the PVN (Di et al., 2003, 2005b).

Whereas the enhancement of mEPSC frequency was observed in approximately half of gastric-related PVN neurons, the DEXand AEA-induced decreases in mEPSC frequency were observed in all cells. The rapid enhancement of mEPSC frequency was not reported in neuroendocrine cells (Di et al., 2003, 2005b), which could indicate a functional difference in the response characteristics of these two cell groups. Interestingly, glucocorticoids were shown to elicit a facilitation of GABA release onto magnocellular neuroendocrine cells over several minutes, but this was mediated by retrograde nitric oxide actions and not by activation of presynaptic TRPV receptors (Di et al., 2005b, 2009). Thus, PVN neuron activity would be expected to be inhibited over several minutes of exposure to glucocorticoids, via suppression of glutamate release and enhancement of GABA release.

\section{ACTIVATION OF TRPV RECEPTORS}

We also observed a significant transient increase in mEPSC frequency within the first few min of DEX and AEA application in about $50 \%$ of gastric-related preautonomic PVN neurons, which was mimicked by capsaicin and the TRPV4-selective agonist 4$\alpha$-PDD and was therefore most likely due to activation of TRPV receptors. The present results are consistent with the hypothesis that both TRPV1 and TRPV4 are functional in the nucleus. Functional TRPV1 receptors have been reported in the PVN previously (Li et al., 2004), and it is possible that glucocorticoid-mediated release of AEA represents an endogenous means of activating these receptors (Smart et al., 2000). The initial excitatory phase of the biphasic response was blocked by the non-selective TRPV antagonist ruthenium red and was eliminated in the presence of combined antagonists to TRPV1 and TRPV4 receptors. However, selective antagonism of TRPV1 only partially blocked the effect, consistent with previous reports (Wenger et al., 2003; Karlsson et al., 2005). Glutamate release was also enhanced by the TRPV4 agonist $4-\alpha-P D D$, suggesting that TRPV4 receptors contribute to the facilitatory response to DEX and AEA (Vriens et al., 2004). Indeed, TRPV1 receptors are present in the PVN at presynaptic glutamatergic terminals (Mezey et al., 2000; Li et al., 2004; Cristino et al., 2006), and TRPV4 receptors have been identified in the hypothalamus (Guler et al., 2002; Carreno et al., 2009). In a subset of gastric-related circuits, therefore, AEA or DEX act first to activate presynaptically located TRPV receptors and enhance glutamate release, and subsequently to activate $\mathrm{CB} 1$ receptors and suppress glutamate release. In an extension of previous findings (Di et al., 
2005b) that also showed glucocorticoid effects on synaptic release to be prevented by blocking G-protein-mediated responses in the recorded neuron, our data are consistent with a model in which an $\mathrm{eCB}$ or other retrograde messenger is released by rapid, G-proteinmediated glucocorticoid actions on gastric-related preautonomic neurons in the PVN.

The TRPV receptors (TRPV1-6) are a family of ligand-gated, non-selective cation channels with high $\mathrm{Ca}^{2+}$ permeability (Montell, 2001). They are activated by a wide range of stimuli (Nilius et al., 2003), including thermal, mechanical, and osmotic stimuli and endogenous lipids, including AEA, NADA, and arachidonic acid metabolites (Watanabe et al., 2003). Capsaicin has been demonstrated to significantly increase the frequency of mEPSCs (but not mIPSCs) without changing mEPSC amplitude or decay time constant in presympathetic PVN neurons (Li et al., 2004). These data are consistent with another study showing that capsaicin stimulates glutamate release from hypothalamic slices (Sasamura et al., 1998). A presynaptic effect of capsaicin on neurotransmitter release was also shown in feeding-related autonomic brainstem areas (Jin et al., 2004; Derbenev et al., 2006). Li et al. (2004) reported that selective TRPV1 blockade prevented the averaged effect of capsaicin, but did not report effects on individual neurons. A recent report indicated that TRPV1-mediated responses were restricted to liver-related preautonomic PVN neurons, and that this effect was eliminated in a model of type 1 diabetes (Gao et al., 2012) due to receptor internalization. This mechanism of diabetes-induced TRPV1 plasticity was previously identified in gastric-related preganglionic parasympathetic motor neurons of the dorsal motor nucleus of the vagus (Zsombok et al., 2011). Our data indicating that TRPV1 activates inputs to gastric-related PVN cells, in addition to liver-related cells described previously (Gao et al., 2012), suggest that TRPV1 modulation of glutamate release is not limited to cells regulating a specific organ system. It is also possible that individual PVN neurons regulate more than one digestive visceral organ via the vagus nerve, possibly via circuits within the vagal complex. However, expression of DEX-induced, TRPV-mediated excitation of glutamate release was not ubiquitous, occurring in approximately $40-50 \%$ of the pre-gastric neurons we recorded, which suggests that only a subpopulation of pre-gastric neurons within the PVN contain glucocorticoid-induced TRPV receptor activity.

We also found that the effect of capsaicin persisted in null mutant mice lacking TRPV1, consistent with the residual effect in the presence of TRPV1 antagonists. In these mice, and in rats, a selective TRPV4 agonist increased mEPSC frequency. The concept of both TRPV1 and TRPV4 operating in concert is not surprising, since recent work suggests an involvement of TRPV1 and/or TRPV4 in osmoregulation, where a possible interaction occurs between the receptors to mediate osmosensitivity (Sharif Naeini et al., 2006; Cohen, 2007). Hypotonicity activates TRPV4 (Watanabe et al., 2003; Vriens et al., 2004); hypertonicity activates TRPV1, or possibly a novel TRPV1 splice variant, found in the lamina terminalis and in magnocellular neurons of the PVN, which is present in TRPV1 ${ }^{-/-}$mice (Schumacher et al., 2000; Ciura and Bourque, 2006; Sharif Naeini et al., 2006; Tian et al., 2006). Our findings suggest a possible cellular mechanism by which the TRPV receptor family (i.e., TRPV1, TRPV4) operate in concert to maintain homeostatic autonomic functions in addition to osmoregulation.

In addition to being eCBs, AEA, and NADA are functional agonists at TRPV1 (Di Marzo et al., 1994; Zygmunt et al., 1999; Smart et al., 2000). TRPV1-mediated effects of the "endocannabinoids" AEA and NADA have been described in the brainstem (Derbenev et al., 2006; Sharkey et al., 2007) and the striatum (Maccarrone et al., 2008). These results demonstrated a functional role for TRPV1-mediated effects of eicosanoid-derived endovanilloids/endocannabinoids in the brain, similar to pharmacological actions in transfected cells (van der Stelt et al., 2005). Additionally, AEA can modulate TRPV4 receptor activity indirectly due to enzymatic hydrolysis to arachidonic acid and metabolism of arachidonic acid by cytochrome p450 (Watanabe et al., 2003), further supporting its role as an endogenous vanilloid. Our results are consistent with the hypothesis that endocannabinoids/endovanilloids, after either exogenous agonist application or endogenously induced release by DEX, can activate CB1, TRPV1, and TRPV4 receptors in the PVN.

\section{POSSIBLE PHYSIOLOGICAL RELEVANCE}

One possible functional role for the biphasic action of DEX in a subset of preautonomic neurons is to regulate the response bandwidth of these cells during transitions from low to high glucocorticoid levels. In neurons that are relatively quiescent prior to glucocorticoid exposure, a reduction in excitatory input would not be expected to have large effects. However, activation of TRPV receptors may "prime" the system for the eventual reduction in activity caused by CB1 receptor-mediated reduction in excitation and subsequent orexigenic activity. Alternatively, specific synapses may be differentially regulated by each receptor type. In either case, rapid and transient responses in centrally projecting neurons, whose activity is relayed to the next neuron in a synaptic chain with high fidelity, may allow for immediate changes in gastric modulation. Release of eCBs is thought to be "on demand" and to correspond to increases in cellular activity (Di Marzo et al., 1994). The transient increase in excitatory synaptic activity caused by eCB release may result in an increase in the gain of the system, such that the eventual inhibition of input becomes more relevant to the cell than it would normally be in the absence of the priming influence of TRPV activation. The broad regulation of neuroendocrine PVN neurons by DEX and AEA (Di et al., 2003, 2005b, 2009; Di and Tasker, 2008), which we also now report in preautonomic neurons, suggests a role for glucocorticoids in coordinating both endocrine and autonomic output from the nucleus. A biphasic regulation of gastric-associated outputs also provides an increased capacity for modulation of these circuits, as well as for plastic changes associated with different feeding-related states.

The present findings in identified gastric-related preautonomic PVN neurons support the hypothesis that feeding and digestive behaviors are rapidly modulated by the activity of glucocorticoids and AEA in the PVN and that this modulation is often biphasic. Typically, excitation of PVN neurons is associated with reduced feeding, while inhibition (or reduced excitation) in the PVN enhances feeding (Grandison and Guidotti, 1977; Sims and Lorden, 1986; Kow and Pfaff, 1989). The transient excitatory effect of eCB release would likely suppress gastric activity whereas 
the delayed, long-term inhibitory effects would increase gastric function relative to the previous relaxed state. The polysynaptic projection of these neurons to the stomach implicates them in the autonomic regulation of gastric function, and suggests a direct link, therefore, between the rapid modulatory actions of glucocorticoids and eCBs and feeding/digestive behaviors.

\section{REFERENCES}

Cano, G., Card, J. P., Rinaman, L., and Sved, A. F. (2000). Connections of Barrington's nucleus to the sympathetic nervous system in rats. $J$. Auton. Nerv. Syst. 79, 117-128.

Cano, G., Sved, A. F., Rinaman, L., Rabin, B. S., and Card, J. P. (2001). Characterization of the central nervous system innervation of the rat spleen using viral transneuronal tracing. J. Comp. Neurol. 439, 1-18.

Carreno, F. R., Ji, L. L., and Cunningham, J. T. (2009). Altered central TRPV4 expression and lipid raft association related to inappropriate vasopressin secretion in cirrhotic rats. Am. J. Physiol. Regul. Integr. Comp. Physiol. 296, R454-R466.

Caterina, M. J. (2007). Transient receptor potential ion channels as participants in thermosensation and thermoregulation. Am. J. Physiol. Regul. Integr. Comp. Physiol. 292, R64-R76.

Ch'ng, T. H., Spear, P. G., Struyf, F., and Enquist, L. W. (2007). Glycoprotein D-independent spread of pseudorabies virus infection in cultured peripheral nervous system neurons in a compartmented system. J. Virol. 81, 10742-10757.

Ciura, S., and Bourque, C. W. (2006). Transient receptor potential vanilloid 1 is required for intrinsic osmoreception in organum vasculosum lamina terminalis neurons and for normal thirst responses to systemic hyperosmolality. J. Neurosci. 26, 9069-9075.

Cohen, D. M. (2007). The transient receptor potential vanilloidresponsive 1 and 4 cation channels: role in neuronal osmosensing and renal physiology. Curr. Opin. Nephrol. Hypertens. 16, 451-458.

Cristino, L., de Petrocellis, L., Pryce, G., Baker, D., Guglielmotti, V., and Di Marzo, V. (2006). Immunohistochemical localization of cannabinoid type 1 and vanilloid transient receptor potential vanilloid type 1 receptors in the mouse brain. $\mathrm{Neu}$ roscience 139, 1405-1415.

Dallman, M. F. (2003). Fast glucocorticoid feedback favors 'the munchies.' Trends Endocrinol. Metab. 14, 394-396.

Davis, S. F., Williams, K. W., Xu, W., Glatzer, N. R., and Smith, B. N. (2003). Selective enhancement of synaptic inhibition by hypocretin (orexin) in rat vagal motor neurons: implications for autonomic regula-

Derbenev, A. V., Monroe, M. J., Glatzer, N. R., and Smith, B. N. (2006). Vanilloid-mediated heterosynaptic facilitation of inhibitory synaptic input to neurons of the rat dorsal motor nucleus of the vagus. $J$. Neurosci. 26, 9666-9672.

Derbenev, A. V., Stuart, T. C., and Smith, B. N. (2004). Cannabinoids suppress synaptic input to neurones of the rat dorsal motor nucleus of the vagus nerve. J. Physiol. (Lond.) 559, 923-938.

Di, S., Boudaba, C., Popescu, I. R., Weng, F. J., Harris, C., Marcheselli, V. L., et al. (2005a). Activitydependent release and actions of endocannabinoids in the rat hypothalamic supraoptic nucleus. J. Physiol. (Lond.) 569, 751-760.

Di, S., Malcher-Lopes, R., Marcheselli, V. L., Bazan, N. G., and Tasker, J. G. (2005b). Rapid glucocorticoidmediated endocannabinoid release and opposing regulation of glutamate and gamma-aminobutyric acid inputs to hypothalamic magnocellular neurons. Endocrinology 146, 4292-4301.

Di, S., Malcher-Lopes, R., Halmos, K. C., and Tasker, J. G. (2003). Nongenomic glucocorticoid inhibition via endocannabinoid release in the hypothalamus: a fast feedback mechanism. J. Neurosci. 23, 4850-4857.

Di, S., Maxson, M. M., Franco, A., and Tasker, J. G. (2009). Glucocorticoids regulate glutamate and GABA synapse-specific retrograde transmission via divergent nongenomic signaling pathways. J. Neurosci. 29, 393-401.

Di, S., and Tasker, J. G. (2008). Rapid synapse-specific regulation of hypothalamic magnocellular neurons by glucocorticoids. Prog. Brain Res. 170, 379-388.

Di Marzo, V., Fontana, A., Cadas, H., Schinelli, S., Cimino, G., Schwartz, J. C., et al. (1994). Formation and inactivation of endogenous cannabinoid anandamide in central neurons. Nature 372, 686-691.

Evanson, N. K., Tasker, J. G., Hill, M. N., Hillard, C. J., and Herman, tion. J. Neurosci. 23, 3844-3854.

\section{ACKNOWLEDGMENTS}

We thank Dr. L. Enquist for supplying the PRV-152, Dr. Y. Lee for the TRPV1 knockout mice. This work was supported by NIH R01 DK080101 (Bret N. Smith), R01 DK056132 (Bret N. Smith), and R01 MH066958 (Jeffrey G. Tasker).

J. P. (2010). Fast feedback inhibition of the HPA axis by glucocorticoids is mediated by endocannabinoid signaling. Endocrinology 151, 4811-4819.

Gamse, R. (1982). Capsaicin and nociception in the rat and mouse. Possible role of substance P. Naunyn Schmiedebergs Arch. Pharmacol. 320, 205-216.

Gao, H., Miyata, K., Bhaskaran, M. D., Derbenev, A. V., and Zsombok, A. (2012). Transient receptor potential vanilloid type 1-dependent regulation of liver-related neurons in the paraventricular nucleus of the hypothalamus diminished in the type 1 diabetic mouse. Diabetes 61 , 1381-1390.

Glatzer, N. R., Derbenev, A. V., Banfield, B. W., and Smith, B. N. (2007). Endomorphin-1 modulates intrinsic inhibition in the dorsal vagal complex. J. Neurophysiol. 98, 1591-1599.

Glatzer, N. R., Hasney, C. P., Bhaskaran, M. D., and Smith, B. N. (2003). Synaptic and morphologic properties in vitro of premotor rat nucleus tractus solitarius neurons labeled transneuronally from the stomach. J. Comp. Neurol. 464, 525-539.

Grandison, L., and Guidotti, A. (1977). Stimulation of food intake by muscimol and beta endorphin. Neuropharmacology 16, 533-536.

Guler, A. D., Lee, H., Iida, T., Shimizu, I., Tominaga, M., and Caterina, M. (2002). Heat-evoked activation of the ion channel, TRPV4. J. Neurosci. 22, 6408-6414.

Irnaten, M., Neff, R. A., Wang, J., Loewy, A. D., Mettenleiter, T. C., and Mendelowitz, D. (2001). Activity of cardiorespiratory networks revealed by transsynaptic virus expressing GFP. J. Neurophysiol. 85, 435-438.

Jin, Y. H., Bailey, T. W., Li, B. Y., Schild, J. H., and Andresen, M. C. (2004). Purinergic and vanilloid receptor activation releases glutamate from separate cranial afferent terminals in nucleus tractus solitarius. J. Neurosci. 24, 4709-4717.

Karlsson, U., Sundgren-Andersson, A. K., Johansson, S., and Krupp, J. J. (2005). Capsaicin augments synaptic transmission in the rat medial preoptic nucleus. Brain Res. 1043, $1-11$.
Kow, L.-M., and Pfaff, D. W. (1989) Responses of hypothalamic paraventricular neurons in vitro to norepinephrine and other feeding-related agents. Physiol. Behav. 46, 265-271.

Larsen, P. J. (1999). Tracing autonomic innervation of the rat pineal gland using viral transneuronal tracing. Microsc. Res. Tech. 46, 296-304.

Li, D. P., Chen, S. R., and Pan, H. L. (2004). VR1 receptor activation induces glutamate release and postsynaptic firing in the paraventricular nucleus. J. Neurophysiol. 92, 1807-1816.

Luther, J. A., Daftary, S. S., Boudaba, C., Gould, G. C., Halmos, K. C., and Tasker, J. G. (2002). Neurosecretory and non-neurosecretory parvocellular neurones of the hypothalamic paraventricular nucleus express distinct electrophysiological properties. J. Neuroendocrinol. 14, 929-932.

Luther, J. A., and Tasker, J. G. (2000). Voltage-gated currents distinguish parvocellular from magnocellular neurones in the rat hypothalamic paraventricular nucleus. J. Physiol. (Lond.) 523(Pt 1), 193-209.

Maccarrone, M., Rossi, S., Bari, M., De Chiara, V., Fezza, F., Musella, A., et al. (2008). Anandamide inhibits metabolism and physiological actions of 2-arachidonoylglycerol in the striatum. Nat. Neurosci. 11, 152-159.

Marinelli, S., Di Marzo, V., Berretta, N. Matias, I., Maccarrone, M., Bernardi G., et al. (2003). Presynaptic facilitation of glutamatergic synapses to dopaminergic neurons of the rat substantia nigra by endogenous stimulation of vanilloid receptors. $J$. Neurosci. 23, 3136-3144.

Mezey, E., Toth, Z. E., Cortright, D. N., Arzubi, M. K., Krause, J. E., Elde, R., et al. (2000). Distribution of mRNA for vanilloid receptor subtype 1 (VR1), and VR1-like immunoreactivity, in the central nervous system of the rat and human. Proc. Natl. Acad. Sci. U.S.A. 97, 3655-3660.

Montell, C. (2001). Physiology, phylogeny, and functions of the TRP superfamily of cation channels. Sci. STKE 2001, RE1.

Nilius, B., Owsianik, G., Voets, T., and Peters, J. A. (2007). Transient receptor potential cation channels in disease. Physiol. Rev. 87, 165-217. 
Nilius, B., Watanabe, H., and Vriens, J. (2003). The TRPV4 channel: structure-function relationship and promiscuous gating behaviour. Pflugers Arch. 446, 298-303.

Sasamura, T., Sasaki, M., Tohda, C., and Kuraishi, Y. (1998). Existence of capsaicin-sensitive glutamatergic terminals in rat hypothalamus. Neuroreport 9, 2045-2048.

Schumacher, M. A., Moff, I., Sudanagunta, S. P., and Levine, J. D. (2000). Molecular cloning of an N-terminal splice variant of the capsaicin receptor. Loss of N-terminal domain suggests functional divergence among capsaicin receptor subtypes. J. Biol. Chem. 275, 2756-2762.

Sharif Naeini, R., Witty, M. F., Seguela, P., and Bourque, C. W. (2006). An Nterminal variant of Trpvl channel is required for osmosensory transduction. Nat. Neurosci. 9, 93-98.

Sharkey, K. A., Cristino, L., Oland, L. D., Van Sickle, M. D., Starowicz, K., Pittman, Q. J., et al. (2007). Arvanil, anandamide and $\mathrm{N}$-arachidonoyldopamine (NADA) inhibit emesis through cannabinoid CB1 and vanilloid TRPV1 receptors in the ferret. Eur. J. Neurosci. 25, 2773-2782.

Sims, J. S., and Lorden, J. F. (1986). Effect of paraventricular nucleus lesions on body weight, food intake and insulin levels. Behav. Brain Res. 22, 265-281.

Smart, D., Gunthorpe, M. J., Jerman, J. C., Nasir, S., Gray, J., Muir, A. I., et al. (2000). The endogenous lipid anandamide is a full agonist at the human vanilloid receptor (hVR1). Br. J. Pharmacol. 129, 227-230.

Smith, B. N., Banfield, B. W., Smeraski, C. A., Wilcox, C. L., Dudek, F. E., Enquist, L. W., et al. (2000). Pseudorabies virus expressing enhanced green fluorescent protein: a tool for in vitro electrophysiological analysis of transsynaptically labeled neurons in identified central nervous system circuits. Proc. Natl. Acad. Sci. U.S.A. 97, 9264-9269.

Stern, J. E. (2001). Electrophysiological and morphological properties of pre-autonomic neurones in the rat hypothalamic paraventricular nucleus. J. Physiol. (Lond.) 537, 161-177.

Swanson, L. W., and Kuypers, H. G. (1980). The paraventricular nucleus of the hypothalamus: cytoarchitectonic subdivisions and organization of projections to the pituitary, dorsal vagal complex, and spinal cord as demonstrated by retrograde fluorescence double-labeling methods. J. Comp. Neurol. 194, 555-570.

Tempel, D. L., Kim, T., and Leibowitz, S. F. (1993). The paraventricular nucleus is uniquely responsive to the feeding stimulatory effects of steroid hormones. Brain Res. 614, 197-204.

Tian, W., Fu, Y., Wang, D. H., and Cohen, D. M. (2006). Regulation of TRPV1 by a novel renally expressed rat TRPV1 splice variant. Am. J. Physiol. Renal Physiol. 290, F117-F126.

Tominaga, M., and Tominaga, T. (2005). Structure and function of TRPV1. Pflugers Arch. 451, 143-150.

Van Der Stelt, M., and Di Marzo, V. (2004). Endovanilloids. Putative endogenous ligands of transient receptor potential vanilloid 1 channels. Eur. J. Biochem. 271, 1827-1834.

van der Stelt, M., Trevisani, M., Vellani, V., De Petrocellis, L., Schiano Moriello, A., Campi, B., et al. (2005). Anandamide acts as an intracellular messenger amplifying $\mathrm{Ca} 2+$ influx via TRPV1 channels. EMBO J. 24, 3026-3037.
Vriens, J., Watanabe, H., Janssens, A. Droogmans, G., Voets, T., and Nilius, B. (2004). Cell swelling, heat, and chemical agonists use distinct pathways for the activation of the cation channel TRPV4. Proc. Natl. Acad. Sci. U.S.A. 101, 396-401.

Wainwright, A., Rutter, A. R., Seabrook, G. R., Reilly, K., and Oliver, K. R. (2004). Discrete expression of TRPV2 within the hypothalamoneurohypophysial system: implications for regulatory activity within the hypothalamic-pituitary-adrenal axis. J. Comp. Neurol. 474, 24-42.

Watanabe, H., Vriens, J., Prenen, J., Droogmans, G., Voets, T., and Nilius, B. (2003). Anandamide and arachidonic acid use epoxyeicosatrienoic acids to activate TRPV4 channels. Nature 424, 434-438.

Wechselberger, M., Wright, C. L. Bishop, G. A., and Boulant, J. A. (2006). Ionic channels and conductance-based models for hypothalamic neuronal thermosensitivity. Am. J. Physiol. Regul. Integr. Comp. Physiol. 291, R518-R529.

Wenger, T., Ledent, C., and Tramu, G. (2003). The endogenous cannabinoid, anandamide, activates the hypothalamo-pituitary-adrenal axis in CB1 cannabinoid receptor knockout mice. Neuroendocrinology 78 294-300.

Williams, K. W., and Smith, B. N. (2006). Rapid inhibition of neural excitability in the nucleus tractus solitarii by leptin: implications for ingestive behaviour. J. Physiol. (Lond.) 573 395-412.

Williams, K. W., Zsombok, A., and Smith, B. N. (2007). Rapid inhibition of neurons in the dorsal motor nucleus of the vagus by leptin. Endocrinology 148, 1868-1881.
Zsombok, A., Bhaskaran, M. D., Gao, H., and Derbenev, A. V. (2011). Functional plasticity of central TRPV1 receptors in brainstem dorsal vagal complex circuits of streptozotocintreated hyperglycemic mice. J. Neurosci. 31, 14024-14031.

Zygmunt, P. M., Petersson, J., Andersson, D. A., Chuang, H., Sorgard, M., Di Marzo, V., et al. (1999). Vanilloid receptors on sensory nerves mediate the vasodilator action of anandamide. Nature 400, 452-457.

Conflict of Interest Statement: The authors declare that the research was conducted in the absence of any commercial or financial relationships that could be construed as a potential conflict of interest.

Received: 24 September 2012; accepted: 07 January 2013; published online: 31 January 2013.

Citation: Boychuk CR, Zsombok A, Tasker JG and Smith BN (2013) Rapid glucocorticoid-induced activation of TRP and CB1 receptors causes biphasic modulation of glutamate release in gastric-related hypothalamic preautonomic neurons. Front. Neurosci. 7:3. doi: 10.3389/fnins.2013.00003

This article was submitted to Frontiers in Neuroendocrine Science, a specialty of Frontiers in Neuroscience.

Copyright (C) 2013 Boychuk, Zsombok, Tasker and Smith. This is an openaccess article distributed under the terms of the Creative Commons Attribution License, which permits use, distribution and reproduction in other forums, provided the original authors and source are credited and subject to any copyright notices concerning any third-party graphics etc. 